\title{
Frequency, Co-morbidities and outcome of acute kidney injury in elderly admitted patients
}

\author{
Huma Mamun Mahmud', Hormatz Diar Dara Dastoor ${ }^{2}$
}

\begin{abstract}
Objectives: To analyse the frequency, co morbidities and outcome ofAcute Kidney Injury (AKI) in elderly patients.

Methods: This is an observational retrospective study performed in a secondary care Hospital located in Abu Dhabi. Study include adult patients admitted during $01^{\text {st }}$ January 2018 till $31^{\text {st }}$ December 2018 . We uses KDIGO criteria of more than $26.5 \mathrm{micromol} / \mathrm{L}$ increase in serum creatinine within 48 hours or 1.5 times increase from baseline within seven days to define AKI. Patients were followed from admission till discharge from hospital either to Home, to other facility or death. Analysis was done on SPSS version 20.

Results: Total admissions for age 60 and above were 880. AKI was observed in 71 patients (8.0\%). Most common co-morbidity found was hypertension being observed in $85.9 \%$. Renal recovery was observed in $70.4 \%$ out of whom complete recovery was seen in only $32.4 \%$ and rest shows partial recovery. Hemodialysis was required in $16.90 \%$ and death results in $22.5 \%$ of our study patients.

Conclusion: AKI is frequent among elderly admitted patients, commonest co- morbidity in these patients is hypertension. Outcome of AKI in elderly patients is poor with death in $22 \%$ of our patients.
\end{abstract}

KEYWORDS: Acute kidney injury, Old age, Outcome, Elderly, Death.

doi: https://doi.org/10.12669/pjms.36.5.2429

How to cite this:

Mahmud HM, Dastoor HDD. Frequency, Co-morbidities and outcome of acute kidney injury in elderly admitted patients. Pak J Med Sci. 2020;36(5):920-924. doi: https://doi.org/10.12669/pjms.36.5.2429

This is an Open Access article distributed under the terms of the Creative Commons Attribution License (http://creativecommons.org/licenses/by/3.0), which permits unrestricted use, distribution, and reproduction in any medium, provided the original work is properly cited.

\section{INTRODUCTION}

Acute Kidney Injury (AKI) is a rapid decline in renal functions. KDIGO (Kidney disease initiatives in global outcome) guidelines defines AKI as increase in $\mathrm{SCr}$ (serum creatinine) by more than or equal to $0.3 \mathrm{mg} / \mathrm{dl}$ (or $26.5 \mathrm{micromol} / \mathrm{L}$ ) within 48

1. Dr. Huma Mamun Mahmud, FCPS Nephrology.

2. Dr. Hormaz Dastoor, MD Nephrology.

1-2: Department of Medicine, Division Nephrology Al Rahba Hospital, Seha,

Abu Dhabi, UAE.

Correspondence:

Dr. Huma Mamun Mahmud

Specialist Nephrology,

Medicine Department,

Al Rahba Hospital,

Shahama, Abu Dhabi, UAE.

Email: humamamun@hotmail.com

* Received for Publciation:

March 1, 2020

* Revision Received:

* Revision Accepted: hours or equal to or more than 1.5 times of baseline, known or presumed to have occurred within the prior 7 days. ${ }^{1} \mathrm{AKI}$ is reported in approximately $20 \%$ of hospitalized patients. ${ }^{2}$

A number of studies define AKI in different clinical conditions. AKI often is result of volume depletion, infections ${ }^{3}$, drugs ${ }^{4}$, contrast induced nephropathy, rhabdomyolysis ${ }^{5}$ obstruction, vasculitis or autoimmune disaeses. A number of clinical chronic condition are also associated with acute and chronic renal failure and has been studied extensively like in heart failure and cirrhosis. ${ }^{6}$ Advancing age is a significant risk factor for renal failure. kidney function declines with increasing age and at age above 40 there is a decline of $10 \mathrm{ml}$ / min/decade. ${ }^{7}$

Declining kidney functions, co-morbidities and poly pharmacy in old age increases the risk of acute injury in elderly patients and even minor insults to aging kidneys results in AKI as function is already compromised. Data is limited for renal 
failure management in old age, also treatment options are limited as presence of multiple comorbidities often limit the use of different modes of renal replacement therapies in the elderly patient compromising the renal care. ${ }^{8}$

Incidence of AKI has been defined in one study by Feest TJ, as high as 17 per million yearly in adults under 50 age to 949 per million yearly in 80-89 age group and prostatic disease was found a frequent cause of AkI in old age seen in $25 \%$. Same study also define overall survival was $54 \%$ at 3 months. ${ }^{9}$

Another study defines impaired recovery of AKI in aged patients, including data from 17 studies. This study defined that no renal recovery was in $26 \%$ in young adults and $31.3 \%$ of elderly patients. Limitations of study were variable definitions of $\mathrm{AKI}$, pathogenesis of AKI, criteria of renal recovery, heterogenecity of co-morbidities and use of different study designs. ${ }^{10}$

In our study we attempt to analyse AKI among eldrely patient who required hospital admission. We assessed frequency, co-morbidities, causes, renal survival and the patient survival in these elderly patients as data on AKI is limited in elderly patients.

\section{METHODS}

This is a simple, observational, Single centre study conducted at Al Rahba Hospital, Abu Dhabi with patient induction duration of one year from 01-01-2018 till 31-12-2018. Data collection was done retrospectively. Study started after getting approval from hospital research and ethical committee.

Our study population includes all admissions of adults above 18 years age during specified year for calculation of frequency of AKI in all above 18 age adults. Then we looked at total number of admissions of patients at and above 60 age as elderly age group and we also looked at frequency of AKI in this group to see if the frequency of AKI in all patients and in elderly age group differ. Data for elderly patients was further evaluated in detail for causes and outcome of renal injury in these patients. Data was collected from electronic health record Citrix and was saved electronically. Data was approachable by primary author alone and privacy was maintained. All patient in elderly age group who had AKI admitted and discharged from hospital during specified period were evaluated and included in study population.

AKI was defined as elevation in $\mathrm{SCr}$ of equal or more than 26.5 micromol/L within 48 hours or 1.5 times increase in $\mathrm{SCr}$ from baseline within seven days as per KDIGO criteria. Demographic data was included and all co-morbidities and cause of renal failure were noted. Recovery was defined as complete if there is complete resolution of AKI and partial if $\mathrm{SCr}$ fail to return to baseline SCr. Labs were checked on admission, peak creatinine was marked and $\mathrm{SCr}$ was noted at time of discharge or death. We calculated eGFR by (lab information system) through EPI-CKD equation. Record was made of body weight from electronic records. Biochemistry was processed on COBAS 8000 machine. We further scrutinize those patients in elderly age group who had severe renal injury and required hemodialysis during admission and evaluate if they have more risk factors leading to severe injury in them.

Data was analysed on SPSS version 20. All the categorical data was given in percentages and numerical data as mean and standard deviation. Results were given as text, tables and figures.

\section{RESULTS}

Total number of study patient in elderly age group was 71 , out of which $41(57.7 \%)$ were male. Mean age of patients in elderly age group was $77.20 \pm$ 10.581 , and mean weight was $69.03 \pm 22.423$. Most of our patients 39 were local belonging to United Arab Emirates (UAE), from Gulf Cooperation Council (GCC) 22 and other expats were 10. Table-I shows that frequency of AKI in our study patients was twice as frequently in elderly age group then in all adults above 18 age.

Table-I: Frequency of AKI in all adult admissions above 18 and in elderly age group.

\begin{tabular}{|c|c|c|c|c|}
\hline & $\begin{array}{c}\text { Total number of } \\
\text { hospital admissions }\end{array}$ & $\begin{array}{c}\text { Total number of hospital } \\
\text { admissions who had } \\
\text { AKI }(\%)\end{array}$ & $\begin{array}{l}\text { Number of hospital } \\
\text { admissions in elderly } \\
\text { age group }\end{array}$ & $\begin{array}{c}\text { Number of hospital } \\
\text { admissions in elderly } \\
\text { age group who had } \\
\text { AKI }(\%)\end{array}$ \\
\hline $\begin{array}{l}\text { Number of hospital } \\
\text { admission from } 1^{\text {st }} \\
\text { January } 2018 \text { till } 31^{\text {st }} \\
\text { December } 2018\end{array}$ & 4424 & $193(4.36 \%)$ & 880 & $71(8.0 \%)$ \\
\hline
\end{tabular}


Table-II: Numerical data.

\begin{tabular}{lcc}
\hline & $\begin{array}{c}\text { All AKI study } \\
\text { patients (71) } \\
\text { Mean } \pm \text { SD }\end{array}$ & $\begin{array}{c}\text { AKI patients who } \\
\text { required hemodialysis } \\
\text { (12) Mean } \pm \text { SD }\end{array}$ \\
\hline Age & $77.20 \pm 10.581$ & $77.25 \pm 9.928$ \\
Baseline creatinine & $112.50 \pm 58.651$ & $148 \pm 118$ \\
Maximum creatinine & $240.42 \pm 124.261$ & $375.67 \pm 169.947$ \\
eGFR before AKI & $56.77 \pm 21.706$ & $46.45 \pm 24.760$ \\
eGFR nadir during & $23.89 \pm 14.063$ & $7.08 \pm 7.179$ \\
$\quad$ AKI & & \\
eGFR on discharge & $41.92 \pm 27.054$ & $9.5 \pm 15.401$ \\
Weight & $69.03+22.423$ & $66.67 \pm 22.89$ \\
No of admission days & $19.68+21.513$ & $44.42+28.031$ \\
\hline
\end{tabular}

Numerical data is shown in Table-II. Hypertension was found to be most common associated illness and was seen in $61 / 71(85.9 \%)$, diabetes being second commonest problem seen in $38 / 71(53.5 \%)$. Common co morbidities are given in Fig.1. Most of our patient s were admitted with AKI on admission 52/71(73.2\%) and rest of them 19/71 develop AKI during hospitalization.

Among all patient dehydration was seen in $64.8 \%, 40.8 \%$ of patient were on diuretics and $18.3 \%$ were on angiotensin converting enzyme inhibitor or angiotensin receptor blocker. Rhabdomyolysis was seen in $2.8 \%$, gastroenteritis in $9.8 \%$, contrast induced nephropathy in $1.4 \%$ and no patient had AKI secondary to NSAIDs. We found septicaemia in $28.1 \%$ of all patients and $66.7 \%$ among those who require hemodialysis. Renal recovery is given Fig.2 and Fig.3. Death was observed in $22.5 \%$ of all elderly AKI patients and $75 \%$ in those who had severe AKI requiring hemodialysis.

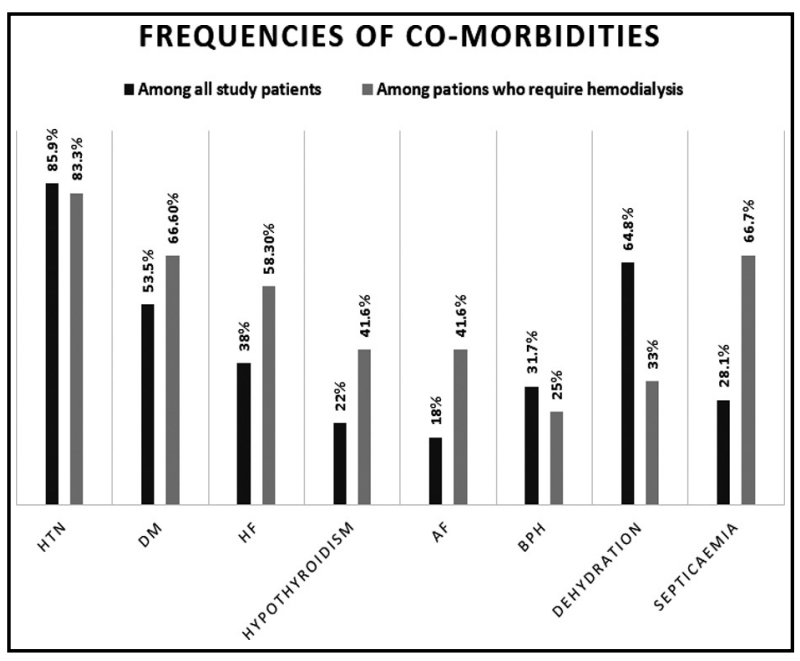

Fig.1: comorbidities among AKI patients.
Table-III: Complications of AKI.

\begin{tabular}{lcc}
\hline & $\begin{array}{c}\text { All AKI study } \\
\text { patients } \\
\text { Number }=71\end{array}$ & $\begin{array}{c}\text { AKI patients } \\
\text { who required } \\
\text { hemodialysis } \\
\text { Number }=12\end{array}$ \\
\hline Hyperkalemia & $15(21.1 \%)$ & $7(58.3 \%)$ \\
Haemoglobin below 10 & $26(36.6 \%)$ & $8(66.6 \%)$ \\
Acidosis & $40(56.3 \%)$ & $12(100 \%)$ \\
Hyponatremia & $24(33.8 \%)$ & $6(50 \%)$ \\
Require mechanical & $23(32.4 \%)$ & $9(75 \%)$ \\
$\quad$ ventilation & $16(22.5 \%)$ & $9(75 \%)$ \\
Death & &
\end{tabular}

\section{DISCUSSION}

Literature shows patient age above 65 are three times more likely to require hospitalization than those in age 45-64 years, with its attached increased helath cost, also length of stay has been defined to be longer in old age group when compared to young age. ${ }^{11}$

Elderly patients has a number of risk factor which increases their risk of developing AKI, like obesity, atherosclerosis, diabetes, hypertension ${ }^{12}$ and AKI has been defined in elderly population to occur more frequently. Incidence of AKI has been defined in one study by Feest TJ, as high as 17 per million yearly in adults under 50 age to 949 per million yearly in 80-89 age group and prostatic disease was found a frequent cause of AkI in old age seen in $25 \%$. Same study also define overall recovery of $54 \%$ at 3 months. ${ }^{9}$

Our study has found frequency of AKI among all adult patients requiring admission in age 18 and above to be $4.36 \%$ and frequency of AKI in all those at and above 60 age is $8 \%$ which is almost

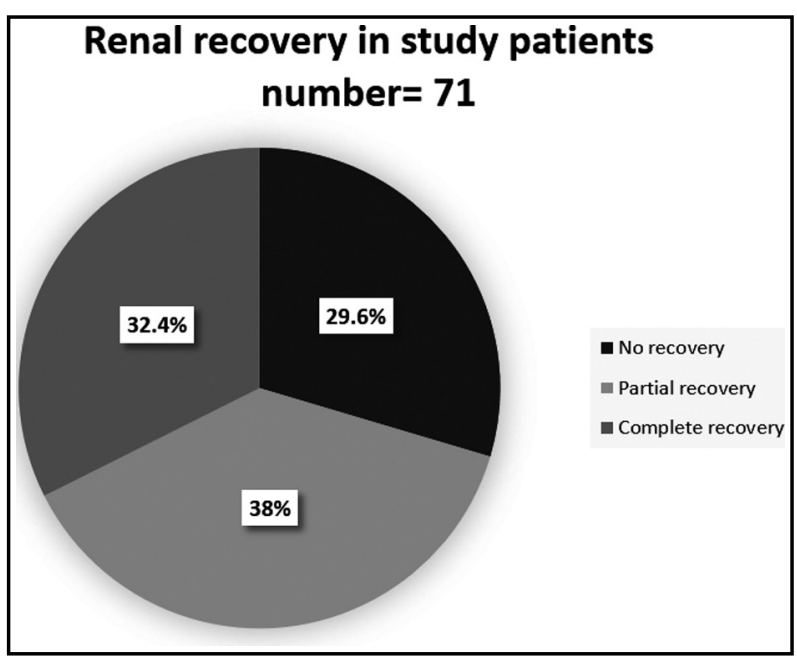

Fig.2: Renal recovery in study patients number $=71$. 


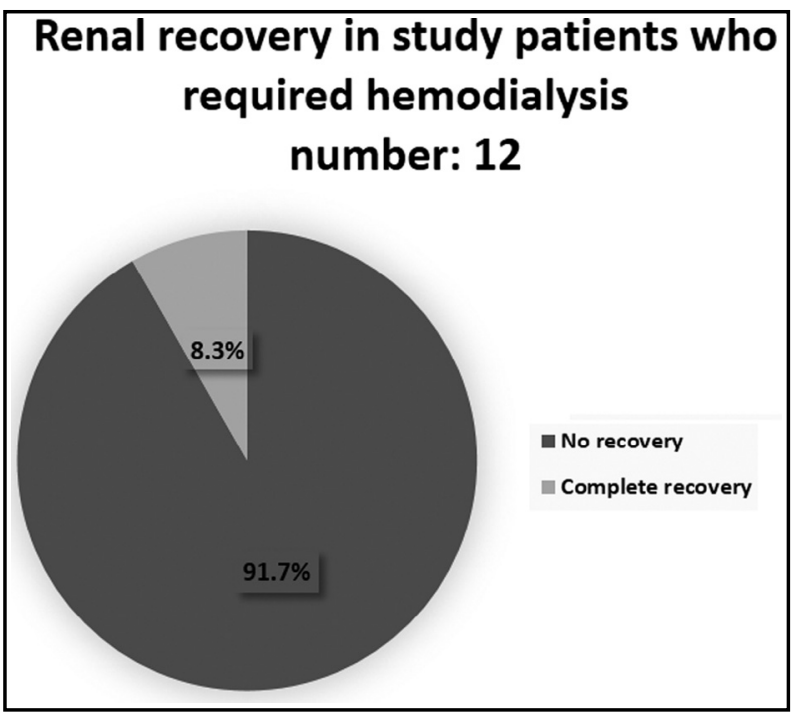

Fig.3: Renal recover in study patients who required hemodialysis number $=12$.

twice the frequency of AKI in all adult admitted patients.

Not too many studies are available to compare frequency of AKI in eldrely patient and most of studies found are prevalence studies. A number of studies has defined that increasing age increases the risk of AKI, and often the presence of multiple co-morbidities and use of multiple drugs in elderly put them at increase risk of AKI, ${ }^{8}$ smoking, atherosclerotic disease ${ }^{13}$ Dyslipidemia, ${ }^{15}$ Obesity, ${ }^{16}$ and male gender ${ }^{17}$ all are associated with an increased risk of renal failure.

Acute kidney injury frequency among hospitalized patient vary from $20-34 \% .^{18,2}$ In our patient we have found frequency of AKI as $4.36 \%$ in all adults which is less than what is defined in other studies. This can be because our hospital is a secondary care hospital with more complicated cases being referred to tertiary care hospitals thereby reducing frequency of acute kidney injury in all hospitalized patients. Also most of the studies giving high frequency of AKI includes patient admission within ICU setting where certainly we see more multiorgan failure patients and higher frequency of AKI whereas our study defines frequency in all admissions to hospital whether in ICU or in general ward.

We found that $73.2 \%$ of our study patients with AKI in elederly age group already had AKI on admission. In one of study NSAID induced renal amage was defined to be seen in $15.3 \%$ of all cases of drug-induced AKI, and accounted for $25 \%$ of cases in those age $65 \mathrm{yr}$ and above. ${ }^{19}$ we do not see NSAIds induced renal injury and attribute it to improving aware ness and cautious use of NSAIDs than previously. About other cause, AKI secondary to contrast was seen in only one patient and rhabdomyolysis was the cause in two of our elderly age group patients.

Septic AKI is independently associated with higher odds of death and longer duration of hospitalization. ${ }^{3}$ In our study we identified sepsis as a major cause of AKI in elderly, frequency being $28.1 \%$ and among severe AKI study patients requiring hemodialysis sepsis alone was cause in $66.7 \%$ of patients. Also we identified dehydration for any reason was present in $64.8 \%$ of our patients with AKI which can also be explained by the fact that $33.8 \%$ of these 71 patients were with a past history of CVA and $66.7 \%$ of them were already bed ridden when admitted and were dependant on care taker for their food and water intake which make them precarious for dehydration.

We found no patient with AKI secondary to glomerular disease and, post renal causes were also not identified in any of our patients and we may relate it to small number of study population.

Mortality in AKI has been defined variably in different studies varying from $40-60 \%{ }^{18,20,21}$ one of studies shows as high as $75 \% .{ }^{12}$ Most of mortality data in studies available is for patient who were critically ill and patients were in ICU settings. AKI has been defined to be an independent mortality risk. ${ }^{22,23}$ We have found that among our patient mortality was seen in $22.5 \%$ among all elderly patients and it was seen in $75 \%$ among those who had severe AKI and who required hemodialysis. This high mortality of $75 \%$ among our hemodialsysis requiring patients is same like defined in most of studies involving studies of AKI among critically ill ICU patients.

Among elderly patients who were having less severe degree of renal injury, few of them were dehydrated, were getting diuretics or suffered mild infections and they heal rapidly once offending agent was removed.Among our surviving elderly patients with AKI renal recovery was observed in $72.4 \%$ in total out of whom complete recovery was observed in $32.4 \%$ only. Among 12/71, who required hemodialysis only $8.3 \%$ shows complete renal recovery.

Limitation of the study: We have not studied causes of AKI in younger patients who are more likely to have these etiologies like trauma and exposure to hard working conditions in extreme 
of high temperatures in UAE resulting in more frequency of AKI secondary to rhabdomyolysis. Our study population involves elderly who were less exposed to physical stress, trauma, and heat exhaustion.

\section{CONCLUSION}

AKI is twice as common in elderly as in general adult population. Hypertension is the commonest co-morbidity found. Septicaemia and dehydration were seen frequently as a contributory factor in renal failure among elderly. Outcome of AKI in elderly patients is poor with death in $22 \%$ of our patients.

\section{Grant support \& financial Disclosures: None.}

\section{REFERENCES}

1. Kellum JA, Lameire N, Aspelin P, Barsoum RS, Burdmann EA, Goldstein SL et al. Kidney disease: Improving global outcomes (KDIGO) acute kidney injury work group. KDIGO clinical practice guideline for acute kidney injury. Kidney Int Suppl. 2012;2(1):1-138. doi: 10.1038/ kisup.2012.1

2. Levey AS, James MT. Acute Kidney Injury. Ann Intern Med. 2017;167(9):ITC66-ITC80. doi: 10.7326/ AITC201711070

3. Bagshaw SM, George C, Bellomo R. Early acute kidney injury and sepsis: A multicentre evaluation. Crit Care. 2008;12(2):R47. doi: 10.1186/cc6863

4. Rennie TJW, De Souza N, Donnan PT, Marwick CA, Davey $\mathrm{P}$, Dreischulte $\mathrm{T}$, et al. Risk of acute kidney injury following community prescription of antibiotics: self-controlled case series. Nephrol Dial Transplant. 2019;34(11):1910-1916 (ISSN: 1460-2385).

5. Talving P, Karamanos E, Skiada D, Lam L, Teixeira PG, Inaba K, et al. Relationship of creatine kinase elevation and acute kidney injury in pediatric trauma patients. J Trauma Acute Care Surg. 2013;74(3):912-916.

6. Durand F, Graupera I, Gines P, Olson JC, Nadim MK. Pathogenesis of Hepatorenal Syndrome: Implications for Therapy. Am J Kidney Dis. 2016;67(2):318-328.

7. Glassock RJ, Winearls C. The global burden of chronic kidney disease: how valid are the estimates? Nephron Clin Pract. 2008;110(1):c39-c46.

8. Mallappallil M, Friedman EA, Delano BG, McFarlane SI, Salifu MO. Chronic kidney disease in the elderly: evaluation and management. Clin Pract (Lond). 2014;11(5):525-535. doi: 10.2217/cpr.14.46

9. Feest TJ, Round A, Hamad S. Incidence of severe acute renal failure in adults: results of a community-based study. BMJ. 1993;306:481-483.

10. Schmitt R, Coca S, Kanbay M, Tinetti ME, Cantley LG, Parikh CR: Recovery of kidney function after acute kidney injury in the elderly: A systematic review and meta-analysis. Am J Kidney Dis. 2008;52:262-271.
11. US Centers for Disease Control and Prevention. Number, percent distribution, rate, days of care with average length of stay, and standard error of discharges from short-stay hospitals, by sex and age: United States, 2010. https:// www.cdc.gov/nchs/data/nhds/2average/2010ave2_ ratesexage.pdf (Accessed on July 16, 2018).

12. Cheung CM, Ponnusamy A, Anderton JG. Management of acute renal failure in the elderly patient: a clinician's guide. Drugs Aging. 2008;25:455-476.

13. Bleyer AJ, Shemanski LR, Burke GL, Hansen KJ, Appel RG. Tobacco, hypertension, and vascular disease: risk factors for renal functional decline in an older population. Kidney Int. 2000;57(5):2072-2079. doi: 10.1046/j.15231755.2000.00056.x

14. Vlassara H, Torreggiani M, Post JB, Zheng F, Uribarri J, Striker GE. Role of oxidants/inflammation in declining renal function in chronic kidney disease and normal aging. Kidney Int. 2009;76(Suppl-114):S3-S11.

15. Fox CS, Larson MG, Leip EP, Culleton B, Wilson PW, Levy D. Predictors of new-onset kidney disease in a community-based population. JAMA. 2004;291:844-850.

16. Foster MC, Hwang SJ, Larson MG, Lichtman JH, Parikh NI, Vasan RS, et al. Overweight, obesity, and the development of stage 3 CKD: the Framingham Heart Study. Am J Kidney Dis. 2008;52(1):39-48. doi: 10.1053/j. ajkd.2008.03.003

17. Baylis C. Sexual dimorphism in the aging kidney: differences in the nitric oxide system. Nat Rev Nephrol. 2009;5(7):384-396. doi: 10.1038/nrneph.2009.90

18. Zhou J, Yang L, Zhang K, Liu Y, Fu P. Risk factors for the prognosis of acute kidney injury under the Acute Kidney Injury Network definition: a retrospective, multicenter study in critically ill patients. Nephrology (Carlton). 2012;17(4):330-337. doi: 10.1111/j.1440-1797.2012.01577.x

19. Kleinknecht D, Landais P, Goldfarb B. Pathophysiology and clinical aspects of drug-induced tubular necrosis in man. Contrib Nephrol. 1987;55:145-158.

20. Schiffl H. Renal recovery from acute tubular necrosis requiring renal replacement therapy: a prospective study in critically ill patients. Nephrol Dial Transplant. 2006;21:1248.

21. Uchino S, Kellum JA, Bellomo R, Doig GS, Morimatsu $\mathrm{H}$, Morgera $\mathrm{S}$, et al. Acute renal failure in critically ill patients: A multinational, multicenter study. JAMA. 2005;294(7):813-818. doi: 10.1001/jama.294.7.813

22. Coca SG, Yusuf B, Shlipak MG, Garg AX, Parikh CR. Long-term risk of mortality and other adverse outcomes after acute kidney injury: a systematic review and metaanalysis. Am J Kidney Dis. 2009;53(6):961-973. doi: 10.1053/j.ajkd.2008.11.034

23. Henry E. W, Paul M, Glenn MC, David GW. Acute Kidney Injury and Mortality in Hospitalized Patients. Am J Nephrol. 2012;35(4):349-355. doi: 10.1159/000337487

\section{Authors' Contribution:}

HMM: Conceived, designed, collect data and data analysis, manuscript writing.

HD: Contributed to data analysis, review and final approval of manuscript. 